\title{
Biaxial deformation behavior of friction stir processed TRIP steel sheets
}

\author{
Imren Ozturk Yilmaz, Onur Saray*, Mumin Yilmaz
}

Dept. of Mechanical Engineering, Bursa Technical University, 16330 Bursa, Turkey

I.O. Yilmaz (0000-0002-5755-5352), O. Saray (0000-0002-9378-3870), M. Yilmaz(0000-0002-4963-5096)

\begin{abstract}
In this study, effects of Friction Stir Processing (FSP) on the biaxial deformation behavior of $1.95 \mathrm{~mm}$ thick TRIP 780 steel sheets were investigated. FSP induced large plastic shear strains imposed at elevated temperature of about $945^{\circ} \mathrm{C}$ have drastically changed both microstructure and flow behavior of the steel. For these reason, after the FSP, significant changes in the microstructural and mechanical properties were obtained. After FSP, initial microstructure of the TRIP-steel transformed into a microstructure that mainly dominated by martensite grains. This transformation resulted with nearly two-fold hardness increase in stir zone. Similarly, lath martensite dominated microstructure elevated the FSPed condition into an ultra-high strength level with expense of room temperature ductility. After FSP, yield strength and UTS increased from 415MPa and $829 \mathrm{MPa}$ to about 1280 $\mathrm{MPa}$ and $1475 \mathrm{MPa}$. Uniform elongation and elongation to failure decreased from $23 \%$ and $11 \%$ to $34 \%$ and $22 \%$ respectively. In accordance to decreased ductility, Erichsen index (EI) of the steel decreased from $9.16 \mathrm{~mm}$ to $4.90 \mathrm{~mm}$ under biaxial stretching conditions In contrast to strength enhancement punch force at EI of TRIP-780 also decreased from $80.6 \mathrm{kN}$ to $45.4 \mathrm{kN}$ respectively. This simultaneous decrease in both $\mathrm{E}_{\mathrm{i}}$ and $\mathrm{F}_{\mathrm{Ei}}$ attributed to increase in cracking tendency of the FSP induced microstructure.
\end{abstract}

Keywords: TRIP steel; AHSS; friction stir processing; formability; Erichsen test

\section{INTRODUCTION}

Steelmakers have tended towards developing steel grades that combine high strength, good ductility and high durability to satisfy light-weighting needs of automotive industry Advanced high strength steels (AHSS), is one of the wellknown and widely used steel sheet product family with a tensile strength range of about 500-1000 MPa [1]. Transformation induced plasticity (TRIP) steel is member of AHSS providing variety combinations of strength and formability via unique microstructure that consist of retained austenite, bainite phases distributed within the ferrittic matrix [2]. Microstructural and mechanical properties for TRIP steel provides great advantages like excellent formability and high capacity of shock absorbance. TRIP steels have been found beneficial in forming of body-in-white with complex geometrical parts. Also, increasing strength of the TRIP steel may provide great advantageous considering the lighweighting goals. It is known that, friction stir processing (FSP) is the unique forceful method that provide an increase in uniaxial strength and/or ductility of metals via phase transformation and/or grain refinement [3]. In FSP, a rotating tool consisting of a shoulder and a pin is plunged into a work piece and then travels in the interested direction. During the movement of the tool, friction between workpiece and shoulder surfaces heats up and softens the process region. Simultaneously, a complicated material flow cycle is constituted via transfer of the softened material surrounding the rotating pin towards the work-piece surface. The cycle is completed by forging back transferred material to the deformation zone by linear movement of the rotating shoulder $[4,5]$. Consequently, intense plastic strains are imposed to processed material at the warm to hot deformation conditions in FSP. To date, there are a few investigations conducted on the FSP of different steel grades such as stainless steels [6-12] , IF-steels [13-16], carbon steels [17-22] and HSLA steels [23, 24]. Also, previous studies on effect FSP of steels mainly concentrated on microstructural evolution, texture formation and strength and ductility after the process. These studies mainly indicated that FSP can be regarded as an a tool to enhance strength by means of microstructural modification with both grain refinement and phase transformation. However, there are limited number of studies on the investigation of
*Corresponding authour

Email: onur.saray@btu.edu.tr
European Mechanical Science, June 2019; 3(2): 56-61 doi: https://doi.org/10.26701/ems.570940

Received: May 28, 2019

Accepted: May 29, 2019 
FSP on the material properties of Transformation-Induced Plasticity (TRIP) steel as a widely used material with unique properties like excellent formability and strain hardenability. In order to close this gap, current study is mainly concentrated on the effect of FSP on the microstructural evolution and mechanical properties TRIP 780 steel. Considering industrial applications of TRIP steels, secondary forming applications are needed to finalize the manufacturing of the BIW parts. In order show the capability and compatibility of the FSPed regions to secondary metal forming applications still need to be explained via multiaxial loading conditions. To the authors best knowledge, on the other hand, post FSP multi-axial plastic deformation behavior of the FSPed TRIP steels have not been investigated.

On the point of view above, present study is concentrated on the revealing relationships between FSP induced microstructural evolutions and uniaxial and multi-axial deformation behaviors of the TRIP steels as a model material to common AHSS.

\section{EXPERIMENTAL METHOD}

The steel utilized in the current study was commercially available TRIP-780. Chemical composition of the as-received material: 0.209 C, $1.68 \mathrm{Si}, 1.65 \mathrm{Mn}, 0.035$ Al, 0.001 P, 0.015 $\mathrm{S}$ and balance Fe (wt. \%). As TRIP steels are widely used in forming of structural automobile parts, $1.95 \mathrm{~mm}$ thickness was selected to investigate possibility of application of the FSP to the AHSS. TRIP-780 steel samples were exposed to FSP using a wolfram-carbide tool with one-pass. The shoulder diameter, pin diameter and pin length were chosen as 16 $\mathrm{mm}, 5 \mathrm{~mm}$ and $0.8 \mathrm{~mm}$ respectively. FSP was applied with tilt angle was 30 and the shoulder plunge depth was kept constant at $0.1 \mathrm{~mm}$ through the process. Based on the results of the several experimental trials, tool rotation speed, processing speed were determined as $1000 \mathrm{rpm}$ and $1.3 \mathrm{~mm} / \mathrm{s}$ as optimum possible process parameters can be applied in a repeatable manner. Processing temperature was monitored using an infrared thermal camera placed near to the tool-sheet interaction region during the FSP processes. Optical microscope (OM) and scanning electron microscopy (SEM) were used to observe the microstructure of TRIP-780 steel samples before and after FSP. Samples for microstructural investigation were sectioned perpendicular to the process direction as shown in Fig. 1(a)) and then etched in 2\% Nital solution for $20 \mathrm{~s}$ after standard grinding and polishing procedures. Mechanical properties before and after FSP were determined using uniaxial tensile tests and micro-hardness tests. Dog-bone shaped specimens with gauge length and gauge width of $12 \mathrm{~mm}$ and $6 \mathrm{~mm}$ were extracted from TRIP780 sheets before and after FSP using wire electric discharge machining (wire-EDM) technique (Fig. 1(b)). The tests were performed using a Shimadzu electro-mechanical load frame equipped with a video type extensometer at a quasi-static strain rate of 1x10-3 s-1. Hardness measurements were carry out with Vickers micro hardness tester under a load of
$500 \mathrm{~g}$ and for $10 \mathrm{~s}$ dwell time (Fig. 1(a)). At least three tests were conducted to check the repeatability of mechanical test results. Flow curves and basic mechanical properties like yield strength, ultimate tensile strength, uniform elongation, elongation to failure, were determined as mean values of the results obtained from at least three companion specimens. Stretch formability behavior of TRIP-780 steel before and after FSP was determined by Erichsen tests according to ASTM E643-15 (Fig. 1(c)). The tests were execute with Erichsen die set added to a servo-hydraulic test rig. FSPed steels carefully fix to coincide the process line to the center of the dome punch. A 20-mm-diameter hemispherical punch was used with a velocity of $10 \mathrm{~mm} / \mathrm{min}$ without lubrication. Draw-in of the specimens was resisted by sheet holder force of $10 \mathrm{kN}$ to assure a pure straining condition. After the tests, punch load (F) and punch displacement (X) data collected using a computer during Erichsen tests. Punch displacement where the maximum punch force $(\mathrm{FEi})$ reached is determined as Erichsen index (Ei). Erichsen tested samples were sectioned and prepared for metallographic examinations to reveal microstructural effective properties on the fracture behavior of the samples.

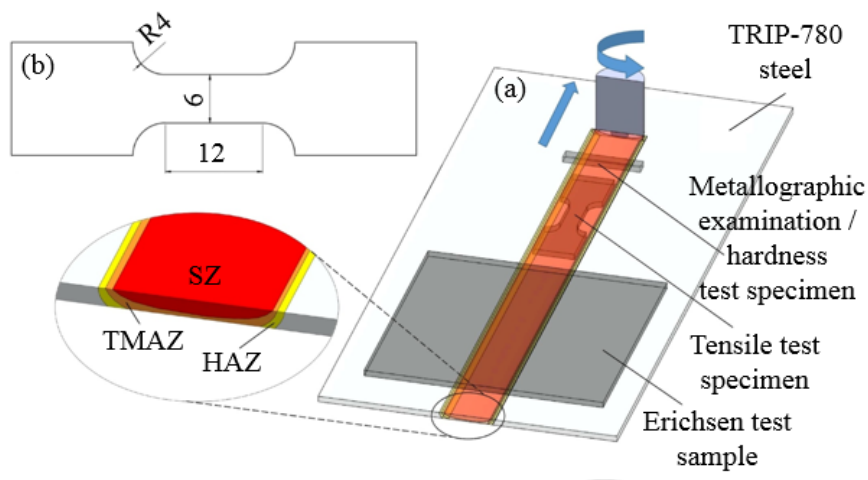

(c)

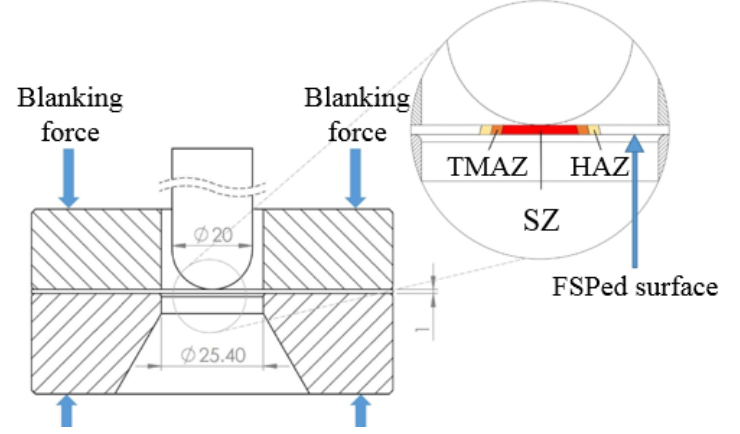

Fig. 1. Schematic diagram of (a) Extraction locations of the test specimens from the FSPed sheet, (b) Dimensions of tensile test specimen, (c) Dimensions of Erichsen test die and placement of the FSPed specimen in the Erichsen die (SZ: Stir zone, TMAZ: Thermo-mechanically affected zone, and HAZ: Heat affected zone).

\section{RESULTS}

\subsection{Microstructural evolution}

Microstructure of the as-received TRIP-780 steel consists of ferrite, bainite and retained austenite phases (Fig. 2). Retained austenite is an important phase and its morphology/ volume fraction of other phases are also a vital factor that influencing the mechanical properties and behavior of retained austenite. 


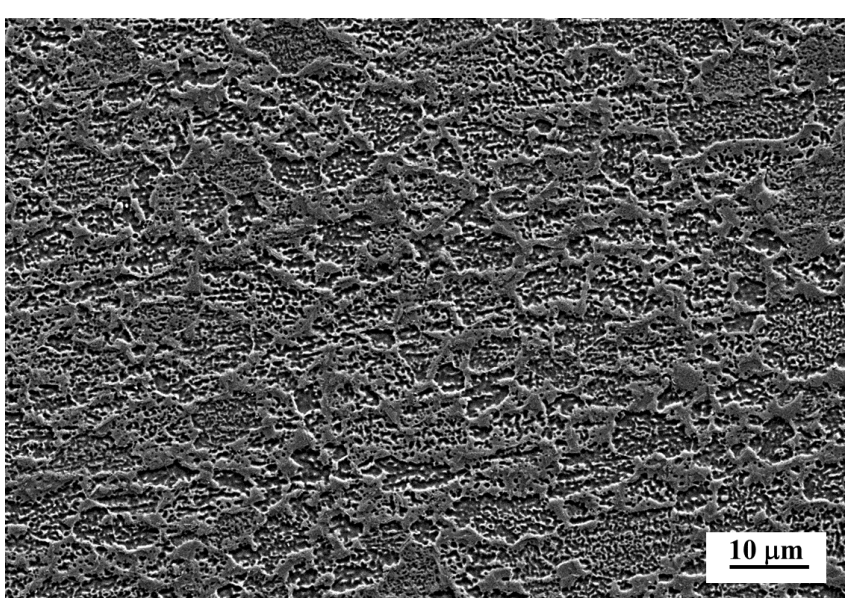

Fig. 2. Microstructure of as received TRIP-780 steel
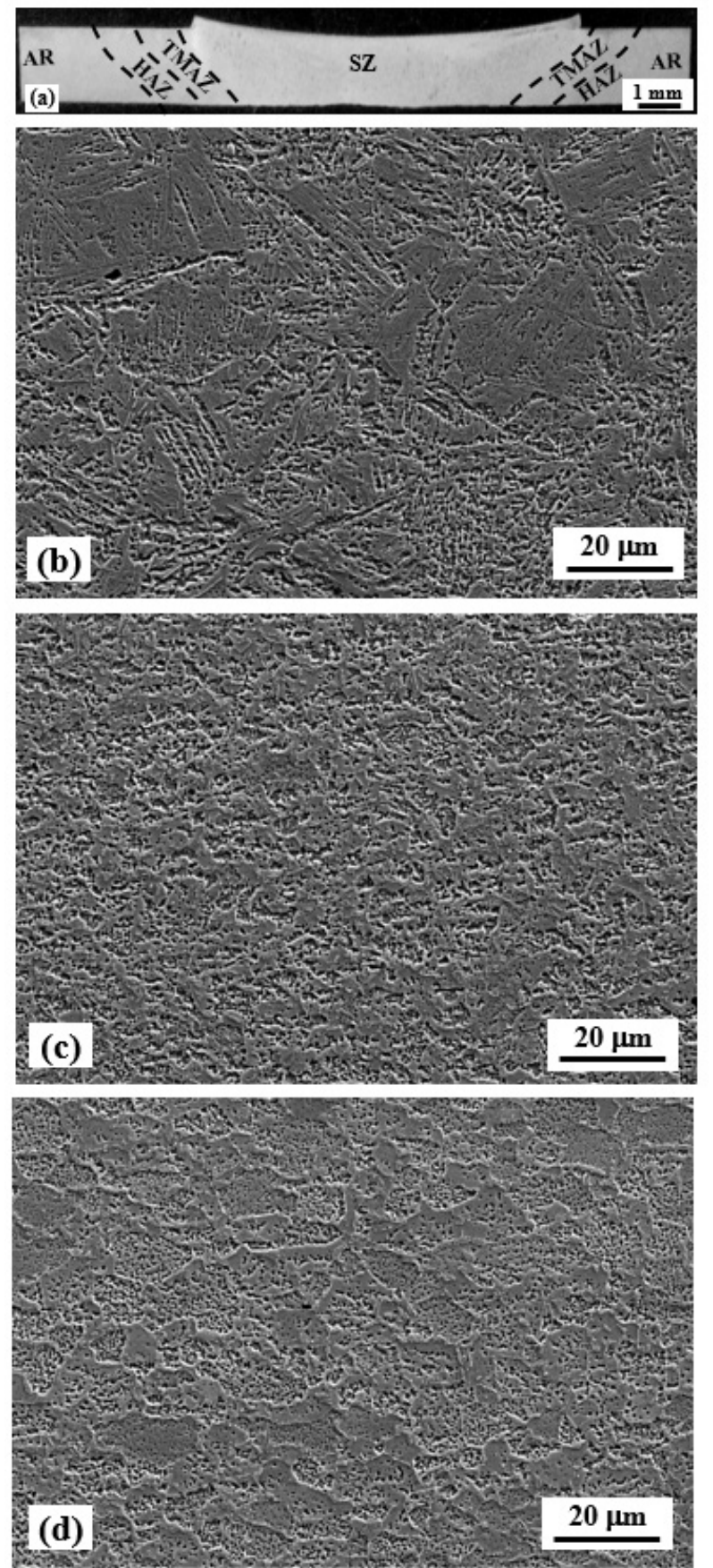

Fig. 3 SEM images (a) a general view of cross-section of the processed zones after FSP. High magnification micrographs showing the (b) SZ, (c) TMAZ (d) HAZ
FSP was successfully applied to TRIP-780 sheets without formation of micro and/or macro scaled cracks. FSP had an extraordinary effect on the microstructure of TRIP-780 steel and formed well characterized deformation zones known as stir zone (SZ), thermo-mechanically affected zone (TMAZ) and heat affected zone (HAZ) (Fig. 3(a)). In stir zone (SZ); as-received microstructure effectively transformed into a martensite dominated microstructure via occurrence of phase transformation (Fig. 3 (b)). Also, thermo-mechanically affected zone (TMAZ) which is the transition zone between the SZ and the HAZ is formed (Fig. 3 (c)). Generally lath martensite phase grains along with coarsened ferrite phase consisted the microstructure of the TMAZ. Therefore, The heat-affected zone (HAZ), which has a microstructure that is only affected by the heat generated during the FSP and reflects features of grain growth. These microstructural variations may be occurred due to deactivation of the dynamic recrystallization at HAZ due to the non-existence of plastic deformation. It is important to note that, the HAZ are difficult to identify after applied FSP conditions.

\subsection{Mechanical properties}

\subsubsection{Hardness}

Micro-hardness profiles obtained by the horizontal scans of the FSPed TRIP-780 sheet were represented in Fig. 4. Microstructural variations through the deformation zones of the FSPed sheet strongly affected the hardness values. Generally, hardness of the TRIP-780 sheet reached to the highest values at the $\mathrm{SZ}$ and this decreased continuously within the TMAZ. Finally, HAZ reflected softening behavior with slightly lower values of hardness compared to that of the as-received steel. The peak hardness values were measured at the nearly center of SZ as $435-488 \mathrm{Hv} 0.5$ which is almost two fold higher than that of the as-received hardness (260 $\mathrm{Hv}$ 0.5). Also, a considerable scatter is observed in hardness values measured through the SZ (Fig. 4).

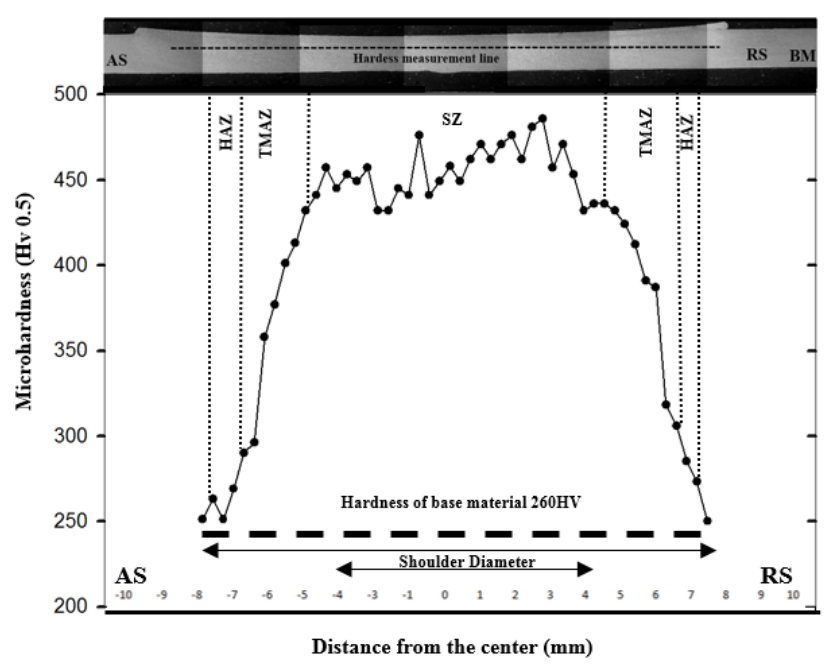

Fig. 4. Hardness evolution of TRIP-780 steel after one pass FSP

\subsubsection{Tensile properties}

The yield strength $\left(\sigma_{\mathrm{y}}\right)$, ultimate tensile strength $\left(\sigma_{\mathrm{uts}}\right)$, uniform elongation $\left(\varepsilon_{\mathrm{u}}\right)$, and elongation to failure $\left(\varepsilon_{\mathrm{f}}\right)$ taken 
from this curves are summarized in Table 1. TRIP-780 increased from $415 \mathrm{MPa}$ and $1280 \mathrm{MPa}$ to about $829 \mathrm{MPa}$ and $1450 \mathrm{MPa}$, respectively. This strength enhancement achieved with a reduction in uniform elongation and elongation to failure. As can be seen from Table 1, uniform elongation and elongation to failure of the as-received material decreased from $23 \%$ and $34 \%$ to $11 \%$ and $22 \%$ respectively after the FSP process.

Table 1. Mechanical properties of as-received and FSPed TRIP-780 steel samples $\left(\sigma_{\mathrm{y}}\right.$ :Yield strength, outs: Ultimate tensile strength, $\varepsilon_{\mathrm{u}}$ : Uniform elongation, $\varepsilon_{f}$ : Elongation to failure

\begin{tabular}{|c|c|c|c|c|}
\hline Condition & $\sigma_{\mathrm{y}}(\mathrm{MPa})$ & $\sigma_{\text {uts }}(\mathrm{MPa})$ & $\varepsilon_{\mathrm{u}}(\%)$ & $\varepsilon_{\mathrm{f}}(\%)$ \\
\hline As-received & 415 & 829 & 23 & 34 \\
\hline FSPed & 1280 & 1475 & 11 & 22 \\
\hline
\end{tabular}

\subsection{Formability}

\subsubsection{Biaxial deformation behavior}

Load (F)-displacement (X) curves obtained from the Erichsen tests are shown in Fig. 5(a). Values of Erichsen index (EI) and punch load at EI (FEI) deduced from F-X curves are given in Table 2. As a common feature of the Erichsen tests, deformation of a sample occurs in an inhomogeneous manner including various stages due to the continuously variating contact conditions between semi-spherical punch surface and sample surface. It has been shown in previous studies [14] that these deformation stages directly affects first order derivative of the punch force with respect to punch displacement $(\mathrm{dF} / \mathrm{dX})$. In order to represent effect of applied FSP on the deformation mode of TRIP-780 steel under biaxial loading conditions, variation of the $\mathrm{dF} / \mathrm{dX}$ through the Erichsen tests were plotted as shown in Fig. 5(b). As can be understood from Fig.5 (a), as-received TRIP-780 steel showed a continuously increasing F-X curve characteristic with a high EI of about 9,16 $\pm 1,3 \mathrm{~mm}$ and FEI of 80,6 $\pm 5,8$ kN FSP of TRIP-780 steel did not considerably affected the curve characteristics but caused a slight decrease in EI and FEI values to about $4,89 \pm 1,1 \mathrm{~mm}$ and $45,4 \pm 2,1 \mathrm{kN}$ respectively (Fig. 5(a)). However, it can also be understood from the Fig. 5(a) that, higher punch loads required for deformation of the FSPed sample compared to as-received counterpart at the same level of punch displacement.

When deformation stages of the as-received and FSPed samples compared, "elastic-plastic bending" (A) and "biaxial plastic bending" (B) stages of the Erichsen tests somewhat affected from the FSP (Fig. 5(b)). TRIP steel after FSP " membrane straining " into the $(\mathrm{C})$ stage deformation is much lower punch force, microstructural properties occurring later explained by mechanical processes and behavior. On the other hand, it is obvious from Fig. 5(b) that, punch displacements within the "membrane straining" $(\mathrm{C})$ and "deformation localization" (D) regimes considerably decreased after FSP.

Macrographs and SEM micrographs taken from the cross-section of the fracture site of as-received and FSPed TRIP-780 steel are represented in Fig. 6 and Fig. 7 respectively. It is obvious from the macrographs of as-received Erichsen tested samples that, fracture occurred with cracks propagated through a crescent shaped crack path around the center of dome (Fig. 6(a)). Microstructure of the cross-section of the fracture sites are represented in Fig. 6(c)-(d). As can be seen Fig. 6 (d) fracture path of the as-received sample consists of boundaries between martensite phase and ferritic matrix. Therefore, it can be concluded that, fracture of the as-received sample occurred with crack propagated through the ferritic matrix. Moreover, several cracks that partly propagated with similar characteristics were evident at the cross section of the as-received Erichsen sample (Fig. 6(d)).
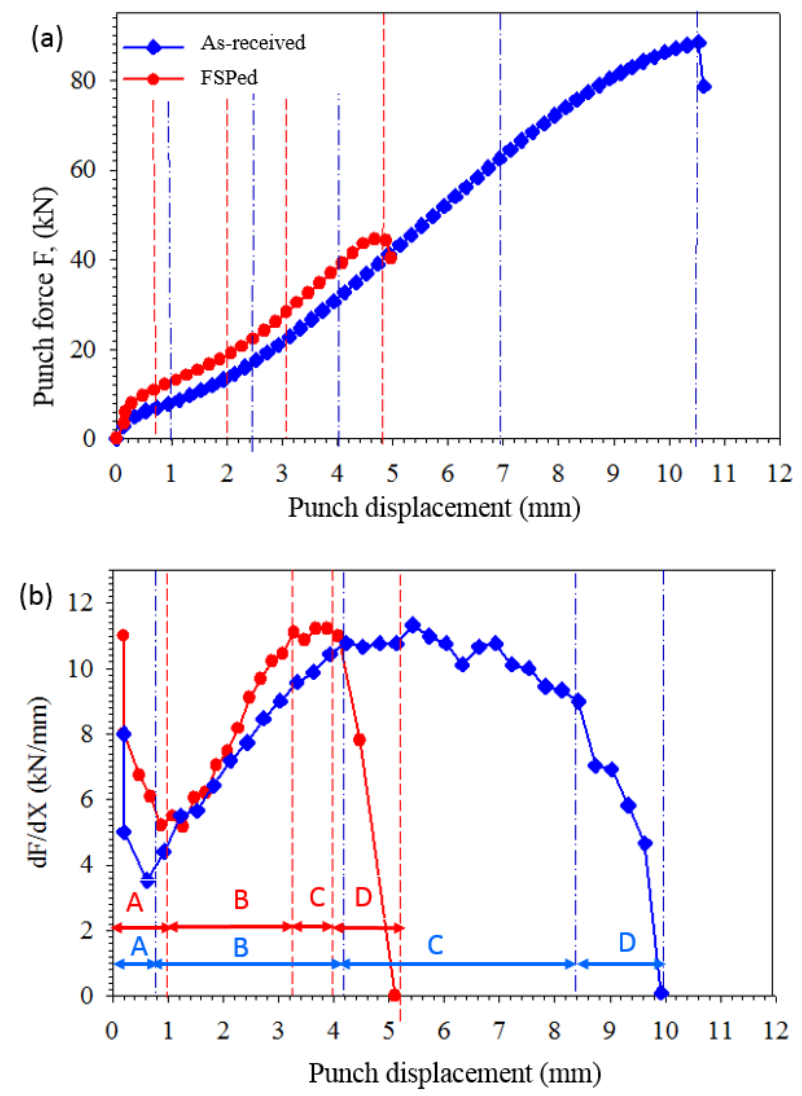

Fig. 5. (a) Punch displacement (X)-punch force (F) curves and (b) $d F / d X-X$ curves and deformation regions of as-received and FSPed TRIP-780 steel

Table 2. Erichsen Index (EI) and punch force (FEI) of as-received and FSPed TRIP-780 samples

\begin{tabular}{|c|c|c|}
\hline Condition & Erichsen index $(\mathrm{El})(\mathrm{mm})$ & Load at Erichsen index $\left(\mathrm{F}_{\mathrm{EI}}(\mathrm{kN})\right.$ \\
\hline As-received & $9,16 \pm 1,3$ & $80,6 \pm 5,8$ \\
\hline FSPed & $4,89 \pm 1,1$ & $45,4 \pm 2,1$ \\
\hline
\end{tabular}

Cross-sectional microstructure of the of the fracture site of FSPed sample indicates that crack propagation characteristics remained unchanged after FSP process i.e. cracks propagated through the ferritic matrix of FSPed TRIP-780 (Fig 7(c)-(d)). Moreover, it is obvious from Fig. 7 (d) that, cracks tend to propagate at the ferrite-martensite interface through the longitudinal direction of the martensite grains. This mainly caused radical changes in the direction of crack propagation (Fig 7(d)). Similarity between the crack propagation behaviors of the as-received and FSPed conditions may be related to martensite phase. In as-received microstructure, martensitic transformation of the initial microstructure du- 


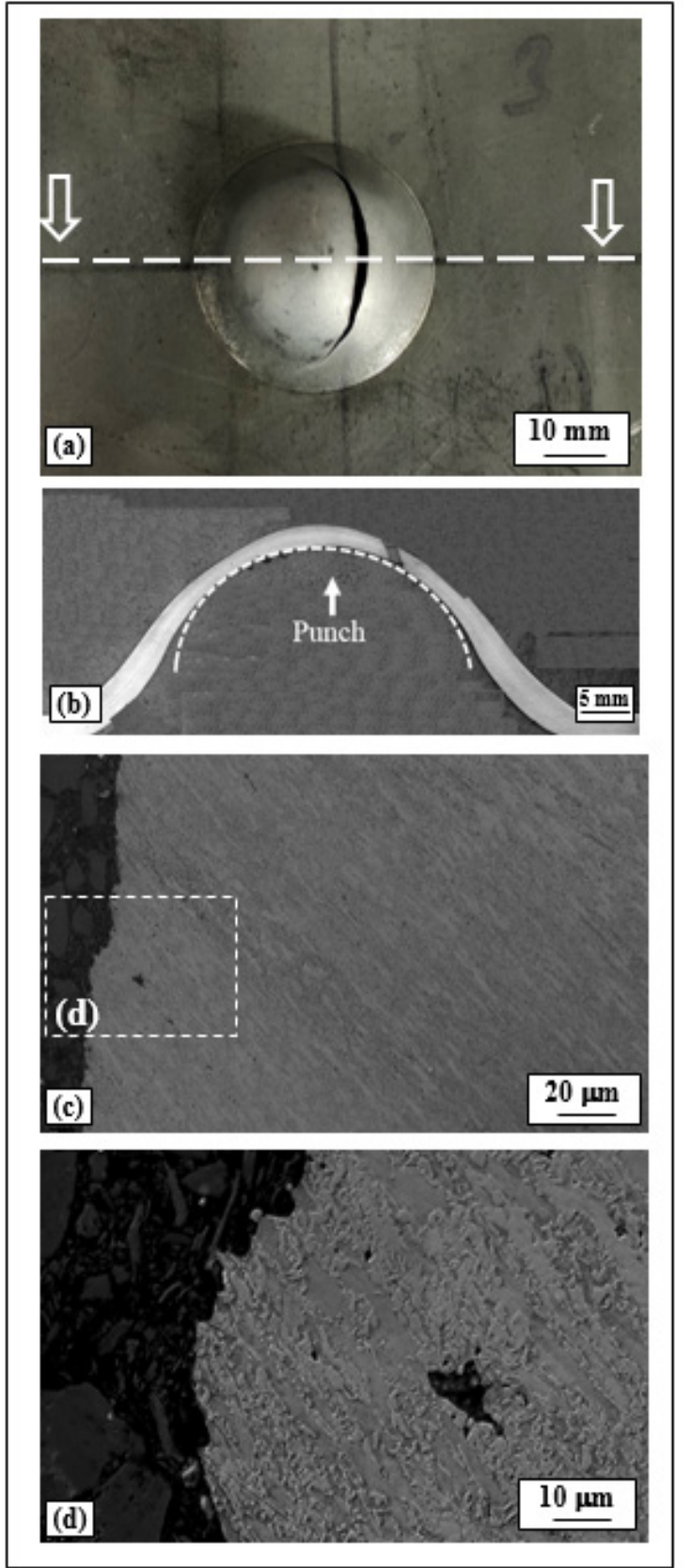

Fig. 6. (a) Top macro-view, (b) Cross-sectional macro-view and (c)-(d) Fracture zone microstructure of the Erichsen tested as-received TRIP-780 steel sample.

ring the biaxial stretching results with formation of the martensite dominated crack path. In the case of FSPed sample, the martensite grains are transformed before the Erichsen test. Consequently, crack path morphology of both conditions have similar features.

\section{CONCLUSION}

In this study, effect of FSP on the microstructure, mechanical properties and impact behavior of TRIP-780 steel are experimentally investigated. The main findings and conclusions of the study can be outlined as follows:

- TRIP-780 steel sheets were successfully processed by position controlled FSP without causing macro damage, cracking or deformation discontinuities.
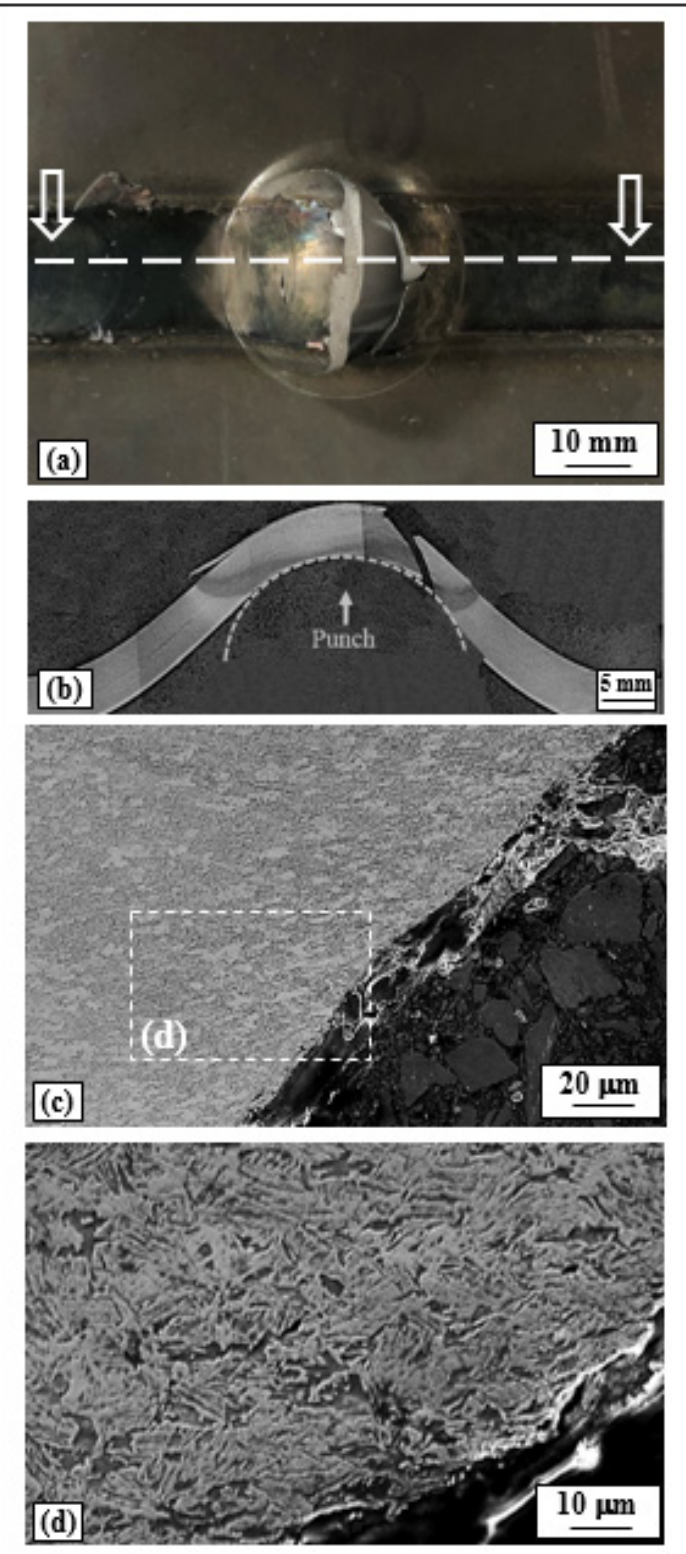

Fig. 7. (a) Top macro-view, (b) Cross-sectional macro-view and (c)-(d) Fracture zone microstructure of the Erichsen tested FSPed TRIP-780 steel sample.

- Microstructural modification obtained by intense thermo-mechanical treatment via FSP increased hardness of the TRIP-780 steel from $260 \mathrm{Hv} 0.5$ to about $480 \mathrm{Hv} 0.5$.

- FSP strongly enhanced strength of TRIP-780 steel yield strength and tensile strength of from $415 \mathrm{MPa}$ and $829 \mathrm{MPa}$ to $1280 \mathrm{Mpa}$ and1475 MPa respectively. However, uniform elongation and elongation to failure values contracted from $23 \%$ and $34 \%$ to $11 \%$ and $22 \%$, respectively.

- As-received TRIP-780 steel shows a high Erichsen index (EI) of about $9.16 \pm 1,3 \mathrm{~mm}$ and punch force at Erichsen index (FEI) of $80.6 \pm 5,8 \mathrm{kN}$. FSP of TRIP-780 steel slightly decreased both EI and FEI values to about $4.89 \pm 1,1 \mathrm{~mm}$ and $45.4 \pm 2,1 \mathrm{kN}$ respectively. Decreased EI of the FSPed TRIP780 steel mainly attributed to increased cracking tendency of the structure as result 
of intense martensitic transformation.

\section{ACKNOWLEDGEMENTS}

This work was supported by Scientific and Technical Research Council of Turkey (TÜBİTAK) under Grant No: 115M649. We would like to thank to support of BEYÇELIK GESTAMP and BORÇELIKK.

\section{REFERENCES}

[1] Paltsev, Y.H., Karplus, V., Kishimoto, P., Reilly, J., Löschel, A., Von Graevenitz, K., Koesler, S. (2018). Impacts of CO2 Mandates for New Cars in the European Union. Transportation Research Record Journal of the Transportation Research Board, 45 (2): 573, DOl:https://globalchange.mit.edu/sites/default/files/MITJPSPGC_Rpt281.pdf

[2] Sugimoto, K., Mukherjee, M. (2017). Automotive Steels Woodhead Publishing https://doi.org/10.1016/C2015-0-00236-2.

[3] Posada, M., Reynolds, A.P., Skinner, M., Halpin, J.P., Jata, K.V., Mahoney, M.W., Mishra, R.S., Semiatin, S.L., Filed, D.P. (2001). The Minerals, Metals \& Materials Society, 159,

[4] Mishra, R.S., Mahoney, M.W. (2007). Friction Stir Welding and Processing. ASM International.

[5] Mishra, R.S., Ma, Z.Y. (2005). Friction stir welding and processing. Materials Science and Engineering: R: Reports, 50 (1-2): 1-78, DOl:http://dx.doi.org/10.1016/j.mser.2005.07.001.

[6] Hajian, M., Abdollah-zadeh, A., Rezaei-Nejad, S.S., et al. (2015). Microstructure and mechanical properties of friction stir processed AISI 316L stainless steel. Materials \& Design, 67: 82-94, DOl:http://dx.doi. org/10.1016/j.matdes.2014.10.082.

[7] Rezaei-Nejad, S.S., Abdollah-zadeh, A., Hajian, M., Kargar, F., Seraj, R. (2015). Formation of Nanostructure in AISI 316L Austenitic Stainless Steel by Friction Stir Processing. Procedia Materials Science, 11: 397-402,DOl:http://dx.doi.org/10.1016/j.mspro.2015.11.008.

[8] Cui, H.B., Xie, G.M., Luo, Z.A., Ma, J., Wang, G.D., Misra, R.D.K. (2016). Microstructural evolution and mechanical properties of the stir zone in friction stir processed AISI201 stainless steel. Materials \& Design, 106: 463-475, DOl:http://doi.org/10.1016/j.matdes.2016.05.106.

[9] Tinubu, O.O., Das, S., Dutt, A., et al. (2016). Friction stir processing of A-286 stainless steel: Microstructural evolution during wear. Wear, 356-357: 94-100. DOl:http://dx.doi.org/10.1016/j.wear.2016.03.018.

[10] [10] Zhang, H., Wang, D., Xue, P., Wu, L.H., Ni, D.R., Ma, Z.Y. (2016) Microstructural evolution and pitting corrosion behavior of friction stir welded joint of high nitrogen stainless steel. Materials \& Design, 110: 802-810,DOI:http://doi.org/10.1016/j.matdes.2016.08.048.

[11] Liu, F.C., Nelson, T.W. (2017). In-situ grain structure and texture evolution during friction stir welding of austenite stainless steel. Materials \& Design, 115: 467-478, DOl:http://doi.org/10.1016/j.matdes.2016.11.066.

[12] Mishra, M.K., Gunasekaran, G., Rao, A.G., Kashyap, B.P., Prabhu, N. (2017). Effect of Multipass Friction Stir Processing on Mechanical and Corrosion Behavior of 2507 Super Duplex Stainless Steel. Journal of Materials Engineering and Performance, 26 (2): 849-860, DOI:10.1007/s11665-016-2470-0.

[13] Chabok, A., Dehghani, K., Ahmadi Jazani M. (2015). Comparing the Fatigue and Corrosion Behavior of Nanograin and Coarse-Grain IF Steels. Acta Metallurgica Sinica, 28: 295-301, Doi:10.1007/s40195014-0196-2.

[14] Sekban, D.M., Saray, O., Aktarer, S.M., Purcek, G., Ma Z.Y. (2015). Microstructure, mechanical properties and formability of friction stir processed interstitial-free steel. Materials Science and Engineering: A, 642: 57-64,DOl:http://dx.doi.org/10.1016/j.msea.2015.06.068.

[15] Wang, W., Xu, R., Hao, Y., et al. (2018). Corrosion fatigue behavior of friction stir processed interstitial free steel. Journal of Materials Science \& Technology, 34(1): 148-156, DOl:https://doi.org/10.1016/j. jmst.2017.11.013.

[16] Zhang, L., Chen, Z., Wang, Y., et al. (2017). Fabricating interstitial-free steel with simultaneous high strength and good ductility with homogeneous layer and lamella structure. Scripta Materialia, 141: 111114, DOl:https://doi.org/10.1016/j.scriptamat.2017.06.044.

[17] Fujii, H., Cui, L., Tsuji, N., Maeda, M., Nakata, K., Nogi K. (2006). Friction stir welding of carbon steels. Materials Science and Engineering: A, 429 (1-2): 50-57, DOl:http://dx.doi.org/10.1016/j. msea.2006.04.118.

[18] Aldajah, S.H., Ajayi, O.O., Fenske, G.R, David S. (2009). Effect of friction stir processing on the tribological performance of high carbon steel. Wear, 267 (1-4): 350-355, DOl:http://dx.doi.org/10.1016/j. wear.2008.12.020.

[19] CChoi, D.H., et al. (2010). Effect of fixed location variation in friction stir welding of steels with different carbon contents. Science and Technology of Welding and Joining, 15(4): 299-304, DOl:https://doi. org/10.1179/136217109X12577814486737.

[20] Khodir, S.A., Morisada, Y., Ueji, R., Fujii H. (2012). Microstructures and mechanical properties evolution during friction stir welding of SK4 high carbon steel alloy. Materials Science and Engineering: A, 558: 572-578, DOl:http://dx.doi.org/10.1016/j.msea.2012.08.052.

[21] Xue, P., Xiao, B.L., Wang, W.G., et al. (2013). Achieving ultrafine dual-phase structure with superior mechanical property in friction stir processed plain low carbon steel. Materials Science and Engineering: A, 575: 30-34, DOl:http://dx.doi.org/10.1016/j.msea.2013.03.033.

[22] Sekban, D.M., Aktarer, S.M., Xue, P., Ma, Z.Y., Purcek, G., (2016). Impact toughness of friction stir processed low carbon steel used in shipbuilding. Materials Science and Engineering: A, 672: 40-48, DOl:http://dx.doi.org/10.1016/j.msea.2016.06.063.

[23] Konkol, P.J., Mathers, J.A., Johnson, R., Pickens J.R. (2003). Friction Stir Welding of HSLA-65 Steel for Shipbuilding. Journal of Ship Production, 19 (3): 159-164,DOI: https://www.ingentaconnect.com/content/sname/jsp/2003/00000019/00000003/art00005.

[24] Nelson, T.W., Rose, S.A. (2016). Controlling hard zone formation in friction stir processed HSLA steel. Journal of Materials Processing Technology, 231: 66-74, DOl:http://dx.doi.org/10.1016/j.jmatprotec.2015.12.013. 